\title{
Total body irradiation as part of conditioning regimens in childhood leukemia-long-term outcome, toxicity, and secondary malignancies
}

\author{
Arne Gruen ${ }^{1}$ Sebastian Exner ${ }^{2}$ Jörn-Sven Kühl ${ }^{3}$ Arend von Stackelberg ${ }^{4}$ Volker Budach ${ }^{1}$. \\ Carmen Stromberger ${ }^{1}$. Dirk Boehmer ${ }^{1}$
}

Received: 4 March 2021 / Accepted: 13 June 2021 / Published online: 19 July 2021

(c) The Author(s) 2021

\begin{abstract}
Background Total body irradiation (TBI) is an established part of conditioning regimens prior to stem cell transplantation in childhood leukemia but is associated with long-term toxicity. We retrospectively analyzed survival, long-term toxicity, and secondary malignancies in a pooled cohort of pediatric patients (pts.) treated with the same TBI regimen.

Methods Analyzed were 109 pts. treated between September 1996 and November 2015. Conditioning treatment according to EBMT guidelines and the ALL SCTped 2012 FORUM trial consisted of chemotherapy (CT) and TBI with 2 Gy b.i.d. on 3 consecutive days to a total dose of $12 \mathrm{~Gy}$. Median follow-up was 97.9 months (2-228 months).

Results Overall survival (OS) in our cohort at 2, 5, and 10 years was 86.1, 75.5, and 63.0\%, respectively. Median survival was not reached. Long-term toxicity developed in 47 pts. After chronically abnormal liver and kidney parameters in 31 and 7 pts., respectively, growth retardation was the most frequent finding as seen in 13 pts. Secondary malignancies were rare $(n=3)$.

Conclusion TBI-containing conditioning regimens in pediatric stem cell transplantation (SCT) are highly effective. Efforts to replace TBI- with CT-containing regimens have only been successful in subgroups of pts. Although we could show long-term toxicity in $43 \%$ of pts., overall survival was $63 \%$ at 10 years. Still, long-term effects such as growth retardation can permanently impact the pts.' quality of life and functioning. Along with new substances, efforts should be undertaken to optimize TBI techniques and accompany the treatment by systematic follow-up programs beyond 5 years to improve detection of rare events.
\end{abstract}

Keywords Survival $\cdot$ Late adverse events $\cdot$ Radiation induced cancer $\cdot$ Pediatric $\cdot$ Cancer of the blood

C. Stromberger and D. Boehmer contributed equally to the manuscript.

Arne Gruen, MD

arne.gruen@charite.de

1 Department for Radiation Oncology and Radiotherapy, Charité-Universitätsmedizin Berlin, corporate member of Freie Universität Berlin, Humboldt-Universität zu Berlin, and Berlin Institute of Health, Campus Virchow-Clinic, Augustenburger Platz 1, 13353 Berlin, Germany

2 Strahlenzentrum Hamburg MVZ, Langenhorner Chaussee 369, 22419 Hamburg, Germany

3 Department for Pediatric Oncology, Hematology and Hemostaseology, University Clinic Leipzig, Liebigstraße 22, Haus 7, 04103 Leipzig, Germany

4 Department for Pediatric Hematology, Oncology and Stem Cell Transplantation, Charité-Universitätsmedizin Berlin, corporate member of Freie Universität Berlin, Humboldt-Universität zu Berlin, and Berlin Institute of Health, Berlin, Germany

\section{Introduction}

TBI reduces the number of leukemic cells and prevents graft rejection in SCT. A randomized study in pediatric pts. showed that TBI-containing induction therapy yielded better survival than CT induction alone [1]. This could be corroborated in a 2011 meta-analysis [2]. Recently, the experimental arm of the randomized ALL SCTped 2012 FORUM trial (NCT01949129) comparing TBI/VP16 conditioning versus CTpoly-CT (either busulfan/fludarabine/ thiotepa or treosulfan/fludarabine/thiotepa) has been closed prematurely due to a steep increase in events when omitting TBI. However, TBI-containing regimens are associated with long-term morbidity like infertility or growth retardation, although exact rates remain unclear [3]. To help better understand the long-term effects of combined treatment approaches, we reviewed a large cohort of pediatric pts. who received the same TBI regimen (from September 1996 to 
November 2015) with respect to survival, long-term toxicity, and secondary malignancies.

\section{Methods}

A total of 201 TBI pts. were treated between September 1996 and November 2015 at the Charité Department of Radiation Oncology (median follow-up 97.9 months, range 2-228 months). After excluding adult pts. and pts. with different regimens, 109 pts. remained for analysis. Inclusion criteria were age $<19$ years, primary or recurrent leukemia, $12 \mathrm{~Gy}$ TBI with single doses of $2 \mathrm{~Gy}$. Conditioning was according to EBMT guidelines [4] and the ALL SCTped 2012 FORUM trial (NCT01949129). Prior whole-brain irradiation had been received by 45 pts. (WBRT; median $18.4 \mathrm{~Gy}$, range 12-24Gy). TBI was initially applied on a cobalt60 machine (1996-2005) and subsequently (2006-2015) on a linear accelerator (linac) with a translation couch and the linac in $0^{\circ}$ position. The patient is thus transported with constant velocity through the beam, first in prone then in supine position. This technique enlarges the field size, improves the photon fluence uniformity, and reduces the depth-dose inhomogeneity [5]. Very young pts. were treated under general anesthesia $(n=5)$. Data were gathered from the internal patient documentation system (SAP, SAP, Walldorf, Germany), OPS and ICD codes and from pts.' files or through direct contact with either treating physicians, pts., or caregivers, and eventually by contacting the residents' registration office. The data were analyzed using IBM SPSS version 22.0 (SPSS, IBM, Armonk, NY, USA). Graphical representation of survival analyses was performed using the Kaplan-Meier method. The Charite ethics board approved this study (EA2/112/21). The informed consent requirement was waived. The research complied with the Declaration of Helsinki.

\section{Results}

For pts.' characteristics see Table 1. OS in our cohort at 2, 5, and 10 years was $86.1,75.5$, and $63.0 \%$, respectively. Me- dian survival was not reached (Fig. 1). Late effects occurred in 47 (43\%) pts. (Fig. 2). Cataracts were found in 3 pts., although the rate of visual impairment was higher. One pt. who had prior $24 \mathrm{~Gy}$ whole brain irradiation (WBRT) later also developed bilateral sicca syndrome. Six pts. had bone/ cartilage damage. One patient (17.6 years) developed severe osteoporosis 5 months after TBI, while two showed femoral/femoral head osteonecrosis 4-5 years after TBI. Two pts. had osteopenia-related fractured vertebral bodies after 4 and 8 years. All pts. had ample exposure to steroids. Growth deficiency (GD) was diagnosed in 13 pts. (median age at treatment 9.4, range 3.4-18.7 years). Four of these pts. had prior WBRT. Hypothyroidism occurred in 7 pts. (12.5\%). Two of these had prior WBRT. Abnormal liver function tests were seen in 31 pts. (40.3\%; male-to-female ratio 6:25). Eight of them died within the FU period. Dyslipidemia was seen in 4 pts. All of them had pathologic serum triglycerides. Secondary malignancies were diagnosed in 3 pts. (2.8\%) after a median latency period of 75.6 months (range 26-120 months). One patient developed Hodgkin's disease (HD) 4 years after treatment on the GMALL 96 protocol. The patient had cobalt-60 TBI and no further irradiation treatments. He was diagnosed 4 years after treatment and relapsed after another 2 years; the patient succumbed to the disease 16 months later. The second patient developed HD 6 years after 12-Gy cobalt-60 TBI on the ALL-BFM 2000 protocol. The patient also had no further irradiation treatments. He was treated for HD and is alive. The third patient developed rhabdomyosarcoma 6 years after 12-Gy photon TBI. The patient was treated for rhabdomyosarcoma and is alive.

\section{Discussion}

In this cohort of 109 pts. treated with the same TBI regimen as part of their conditioning prior to SCT, tumor control is in keeping with published results, with OS at 5 years of $75.5 \%$ and a low recurrence rate of $7.3 \%$ (Fig. 2). In this multimodally treated cohort, late effects cannot be attributed to a single therapy element but are a consequence of combined effects. With complete organ-at-risk (OAR) ex-

Table 1 Patients' characteristics. Our cohort comprises predominantly male pts. with acute lymphatic leukemia (ALL) in CR1 or 2

\begin{tabular}{|c|c|}
\hline Cohort size & $n=109$ \\
\hline Age & 2.4-18.9 years (median 11.2 years) \\
\hline Sex ratio & 34 female: 75 male \\
\hline Diagnoses & $\operatorname{ALL}(n=101)$ other $(\mathrm{AML}=5, \mathrm{CML}=2, \mathrm{NHL}=1 ; n=8)$ \\
\hline Initial study protocol & $\begin{array}{l}\text { 92\% of pts. received initial therapy on or according to a current study protocol (ALL-BFM 90, ALL-BFM 95, ALL- } \\
\text { REZ BFM 96, ALCL 99, ALL-BFM 2000, COALL 06-97, GMALL 06-99, GMALL 08-03) }\end{array}$ \\
\hline Conditioning protocol & $\begin{array}{l}\text { EBMT handbook and guidelines, ALL SCTped } 2012 \text { FORUM trial (TBI was } 6 \times 2 \text { Gy b.i. d. q8 } \mathrm{h} \text { on } 3 \text { consecutive } \\
\text { days, mean lung dose } \sim 10 \mathrm{~Gy} \text { ) }\end{array}$ \\
\hline Prior irradiation & $n=45($ WBRT $n=22 ;$ gonadal boost $n=10 ;$ misc. $n=13)$ \\
\hline
\end{tabular}



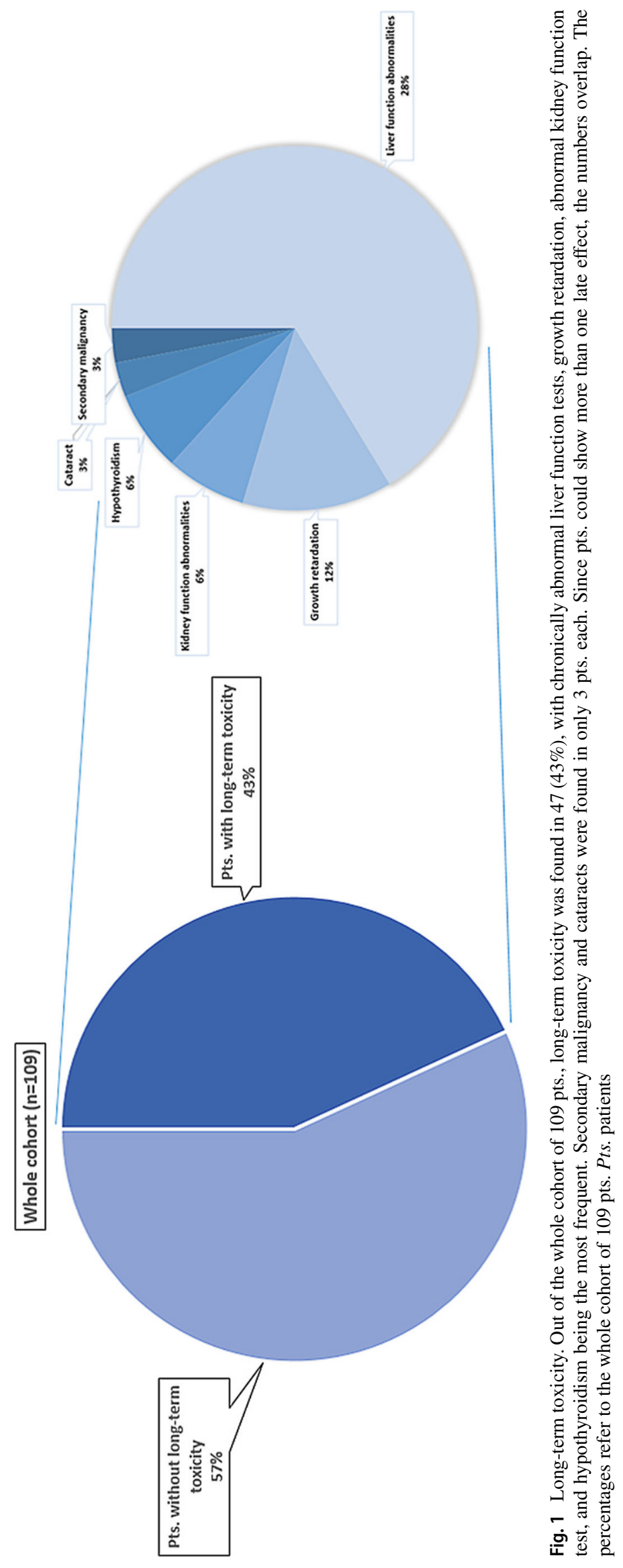


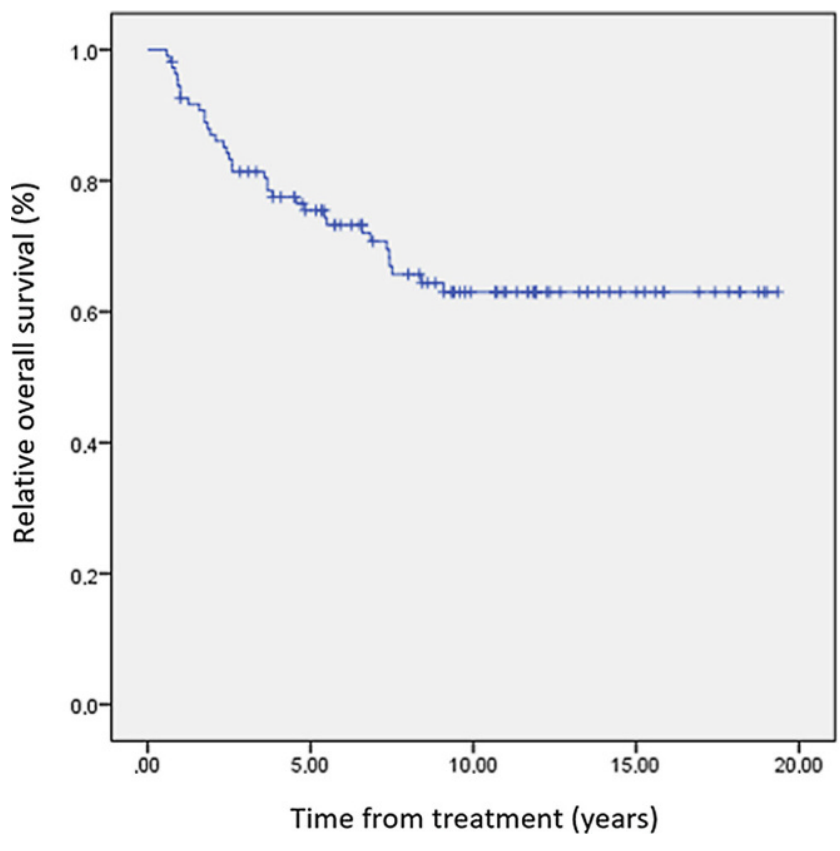

Fig. 2 Overall survival (OS) in our cohort at 2, 5, and 10 years was 86.1, 75.5, and 63.0\%, respectively. Median survival was not reached. Patients treated in CR2 (2nd complete remission) showed similar OS data at 2,5 , and 10 years with $97.8,88.0$, and $65.7 \%$, respectively

posure in TBI though, the estimation of radiation-induced late effects is higher than in focal radiotherapy [6].

GD (24\%) and hypothyroidism (21.2\%) are the most frequent late effects [7], with a median time to onset of hypothyroidism of 50 months [8]. Compared to single-session TBI, fractionated TBI reduces the rate of hypothyroidism from 90 to $15 \%$ [9], which is reflected by the $12.5 \%$ in our cohort. Young age is conversely associated with an increase in GD rates. In a retrospective analysis of 81 very young pts. (median age 1.4 years), $92 \%$ had growth hormone $(\mathrm{GH})$ deficiency with $71 \%$ falling under the $2.5 \%$ growth percentile $[3,10]$, while $80 \%$ still show a growth $>3$ rd percentile [11-13]. In our cohort, $31 \%$ of pts. with GD had prior WBRT, which increases the dose to the pituitary [14].

Fractionated TBI decreases the cataract rate from $>90 \%$ to $30 \%$ at 3 years [15]. In our cohort we saw a cataract rate of only $2.7 \%$, which is probably due to fractionation and the higher median age of 11.2 years.

Restrictive lung disease is seen in $\sim 20 \%$ of pediatric pts. and peaks 3-6 months after TBI/SCT. Restitution is possible within 2 years [16-19]. Thirteen (12\%) of our pts. developed cryptogenic organizing pneumonia (COP) with decreased FEV-1.

The main risk factor for glomerulopathy after TBI/SCT in children is TBI [20]. Grönros et al. analyzed 187 pts. undergoing SCT, 64 pts. had an additional TBI. Fifty healthy children constituted the control group. GFR and effective renal plasma flow were normal prior to therapy. After treat- ment both values were significantly worse with TBI [21]. A study on 1635 adult pts. (median age at SCT 38.5 years) on the other hand could show that a reduction in GFR post TBI and SCT was mainly associated with GVHD [22]. Seven of our pts. developed renal insufficiency with chronically elevated retention parameters ([3]; Fig. 2).

Rösler and co-workers presented a cohort of 216 pts. with irradiation to the liver ( 70 pts. with TBI). With a mean dose to the liver of $5 \mathrm{~Gy}, 17 \%$ of pts. developed mild liver dysfunction [23]. With a mean dose of $12 \mathrm{~Gy}$ we saw 32 pts. (28.4\%) with pathologic serum liver parameters. There was no case of VOD (veno-occlusive disease).

Four pts. in our cohort were diagnosed with dyslipidemia, which is in accordance with two studies showing elevated triglycerides in children after TBI and SCT [24, 25]. Dyslipidemia might be associated with GH deficiency; hence, early GH substitution might normalize serum lipids and thus decrease cardiovascular risk [26, 27].

Secondary malignancies after TBI and SCT are mostly lymphomas (often earlier after SCT) and hematologic malignancies. In most cases they are associated with immune dysregulation and EBV reactivation/infection [28, 29]. Two of our pts. (1.8\%) developed Hodgkin lymphoma (HD) in the FU period. Secondary solid tumors are rare but occur with a two- to threefold risk compared to the normal population. They occur after long latency periods. Young age is an independent risk factor. There is a dose dependency, especially in secondary tumors of the thyroid, salivary glands, bone, connective tissue, and brain [30-35]. One of our pts. developed rhabdomyosarcoma 6 years after treatment. In other publications rates of secondary solid tumors were higher [36-38], especially in younger pts. [30].

There are critical issues and shortcomings concerning this analysis. The retrospective nature of this work alone is susceptible to fault. The pts. in this analysis were not systematically screened, but rather we relied on the available FU data. On the other hand, one might argue that only clinically apparent conditions impair a patient's quality of life and, hence, subclinical deviations could be neglected. The strength and uniqueness of this work is obviously in the large cohort size treated at one institution with the same TBI regimen in combination with a very long FU period. As all pts. were treated with CT and radiation, the adverse events described here result from both modalities, without a possible means of discrimination.

\section{Conclusion}

Tumoricidal effects and immune suppression of TBI facilitating donor cell engraftment are well established. Hence, TBI remains a vital part of conditioning regimens in pts. with risk factors or recurrences prior to SCT and its' omis- 
sion can have detrimental outcome effects. Severe longterm effects seem rare when looking at large cohorts with long FU. But individually, they can pose life-altering events, especially in very young pts. Hence, further optimization of techniques and long-term FU programs for the detection of rare events are warranted. We established helical tomotherapy-based intensity-modulated conformal TBI in children and young adults. With this technique we are able to reduce the dose to critical organs such as the eyes [39], the thyroid, the liver, and the lungs [40]. Losert et al. have proposed a rotatable tabletop system to provide a similar treatment on a regular linac [41]. Total marrow irradiation and total marrow and lymphoid irradiation are targeted forms of radiotherapy that have the potential to decrease toxicity [42]. In the murine model, ultra-high-dose-rate FLASH-TBI has been shown to be beneficial with regard to hematopoiesis preservation in leukemia treatment [43].

Funding Open Access funding enabled and organized by Projekt DEAL.

\section{Declarations}

Conflict of interest A. Gruen, S. Exner, J.-S. Kühl, A. von Stackelberg, V. Budach, C. Stromberger, and D. Boehmer declare that they have no competing interests.

Ethical standards For this article no studies with human participants or animals were performed by any of the authors. All studies mentioned were in accordance with the ethical standards indicated in each case.

Open Access This article is licensed under a Creative Commons Attribution 4.0 International License, which permits use, sharing, adaptation, distribution and reproduction in any medium or format, as long as you give appropriate credit to the original author(s) and the source, provide a link to the Creative Commons licence, and indicate if changes were made. The images or other third party material in this article are included in the article's Creative Commons licence, unless indicated otherwise in a credit line to the material. If material is not included in the article's Creative Commons licence and your intended use is not permitted by statutory regulation or exceeds the permitted use, you will need to obtain permission directly from the copyright holder. To view a copy of this licence, visit http://creativecommons.org/licenses/by/4. $0 /$.

\section{References}

1. Bunin N, Aplenc R, Kamani N et al (2003) Randomized trial of busulfan vs total body irradiation containing conditioning regimens for children with acute lymphoblastic leukemia: a Pediatric Blood and Marrow Transplant Consortium study. Bone Marrow Transplant 32:543-548

2. Gupta T, Kannan S, Dantkale V et al (2011) Cyclophosphamide plus total body irradiation compared with busulfan plus cyclophosphamide as a conditioning regimen prior to hematopoietic stem cell transplantation in pts. with leukemia: a systematic review and metaanalysis. Hematol Oncol Stem Cell Ther 4:17-29

3. Mulcahy Levy JM, Tello T, Giller R et al (2013) Late effects of total body irradiation and hematopoietic stem cell transplant in children under 3 years of age. Pediatr Blood Cancer 60:700-704. https://doi. org/10.1002/pbc. 24252

4. Carreras E, Dufour C, Mohty M, Kröger N (eds) (2019) The EBMT handbook. Hematopoietic stem cell transplantation and cellular therapies. Library of Congress Control Number: 2018960384. https://doi.org/10.1007/978-3-030-02278-5 (open access publication, eBook)

5. Quast U (1985) Physical treatment planning of total-body irradiation: patient translation and beam-zone method. Med Phys 12:567-574. https://doi.org/10.1118/1.595677

6. Lundgaard AY, Hjalgrim LL, Rechner LA et al (2020) The risk of late effects following pediatric and adult radiotherapy regimens in Hodgkin lymphoma. Strahlenther Onkol. https://doi.org/10.1007/ s00066-020-01721-w

7. Kinclová I, Hajtmanová E, Matula P et al (2020) Model-based calculation of thyroid gland normal tissue complication probability in head and neck cancer pts. after radiation therapy. Strahlenther Onkol 196:561-568. https://doi.org/10.1007/s00066-020-01579-y

8. Borgström B, Bolme P (1994) Thyroid function in children after allogeneic bone marrow transplantation. Bone Marrow Transplant 13:59-64

9. Keilholz U, Max R, Scheibenbogen C et al (1997) Endocrine function and bone metabolism 5 years after autologous bone marrow/blood-derived progenitor cell transplantation. Cancer 79:1617-1622. https://doi.org/10.1002/(SICI)1097-0142(1997041 5)79:8<617::AID-CNCR27>3.0.CO;2-\#

10. Cohen A, Rovelli A, Bakker B et al (1999) Final height of pts. Who underwent bone marrow transplantation for hematological disorders during childhood: a study by the working party for late effects-EBMT. Blood 93:4109-4115. https://doi.org/10.1182/blood. V93.12.4109

11. Clement-De Boers A, Oostdijk W, Van Weel-Sipman MH et al (1996) Final height and hormonal function after bone marrow transplantation in children. J Pediatr 129:544-550. https://doi.org/ 10.1016/S0022-3476(96)70119-1

12. Shinagawa T, Tomita Y, Ishiguro $\mathrm{H}$ et al (2001) Final height and growth hormone secretion after bone marrow transplantation in children. Endocr J 48:133-138

13. Couto-Silva AC, Trivin C, Esperou H et al (2000) Changes in height, weight and plasma leptin after bone marrow transplantation. Bone Marrow Transplant 26:1205-1210. https://doi.org/10. 1038/sj.bmt. 1702718

14. Sklar C, Mertens A, Walter A et al (1993) Final height after treatment for childhood acute lymphoblastic leukemia: comparison of no cranial irradiation with 4800 and 2400 centigrays of cranial irradiation. J Pediatr 123:59-64

15. Benyunes MC, Sullivan KM, Deeg HJ et al (1995) Cataracts after bone marrow transplantation: long-term follow-up of adults treated with fractionated total body irradiation. Int J Radiat Oncol Biol Phys 32(7790252):661-670. https://doi.org/10.1016/03603016(94)00392-x

16. Cerveri I, Fulgoni P, Giorgiani G et al (2001) Lung function abnormalities after bone marrow transplantation in children: Has the trend recently changed? Chest 120:1900-1906. https://doi.org/10. 1378/chest.120.6.1900

17. Carlson K, Bäcklund L, Smedmyr B et al (1994) Pulmonary function and complications subsequent to autologous bone marrow transplantation. Bone Marrow Transplant 14:805-811

18. Rovelli A, Pezzini C, Silvestri D et al (1995) Cardiac and respiratory function after bone marrow transplantation in children with leukaemia. Bone Marrow Transplant 16:571-576

19. Schultz KR, Green GJ, Wensley D et al (1994) Obstructive lung disease in children after allogeneic bone marrow transplantation. Blood 84(7949192):3212-3220

20. Frisk P, Bratteby L, Carlson K et al (2002) Renal function after autologous bone marrow transplantation in children: a long-term 
prospective study. Bone Marrow Transplant 29:129-136. https:// doi.org/10.1038/sj.bmt.1703312

21. Grönroos MH, Bolme P, Winiarski J et al (2007) Long-term renal function following bone marrow transplantation. Bone Marrow Transplant 39:717-723. https://doi.org/10.1038/sj.bmt.1705662

22. Hingorani S, Guthrie KA, Schoch G et al (2007) Chronic kidney disease in long-term survivors of hematopoietic cell transplant. Bone Marrow Transplant 39:223-229. https://doi.org/10.1038/sj. bmt. 1705573

23. Rösler P, Christiansen H, Kortmann RD et al (2015) Hepatotoxicity after liver irradiation in children and adolescents: results from the RiSK. Strahlenther Onkol 191:413-420. https://doi.org/10.1007/ s00066-014-0796-9

24. Taskinen M, Saarinen-Pihkala UM, Hovi L et al (2000) Impaired glucose tolerance and dyslipidaemia as late effects after bone-marrow transplantation in childhood. Lancet 356:993-997. https://doi. org/10.1016/S0140-6736(00)02717-3

25. Chow EJ, Simmons JH, Roth CL et al (2010) Increased cardiometabolic traits in pediatric survivors of acute lymphoblastic leukemia treated with total body irradiation. Biol Blood Marrow Transplant 16:1674-1681. https://doi.org/10.1016/j.bbmt.2010.05. 016

26. Carroll PV, Christ ER, Bengtsson BA et al (1998) Growth hormone deficiency in adulthood and the effects of growth hormone replacement: a review. Growth hormone research society scientific committee. J Clin Endocrinol Metab 83:382-395. https://doi.org/ 10.1210/jcem.83.2.4594

27. Maison $P$, Griffin S, Nicoue-Beglah M et al (2004) Impact of growth hormone $(\mathrm{GH})$ treatment on cardiovascular risk factors in GH-deficient adults: a Metaanalysis of Blinded, Randomized, Placebo-Controlled Trials. J Clin Endocrinol Metab 89:2192-2199. https://doi. org/10.1210/jc.2003-030840

28. Witherspoon R, Storb R, Pepe M et al (1992) Cumulative incidence of secondary solid malignant tumors in aplastic anemia pts. given marrow grafts after conditioning with CT alone. Blood 79:289-291. https://doi.org/10.1182/blood.V79.1.289.bloodjournal791289

29. Bhatia S, Ramsay NK, Steinbuch M et al (1996) Malignant neoplasms following bone marrow transplantation. Blood 87:3633-3639

30. Curtis RE, Rowlings PA, Deeg HJ et al (1997) Solid cancers after bone marrow transplantation. N Engl J Med 336:897-904. https:// doi.org/10.1056/NEJM199703273361301

31. Neglia JP, Meadows AT, Robison LL et al (1991) Second neoplasms after acute lymphoblastic leukemia in childhood. N Engl J Med 325:1330-1336. https://doi.org/10.1056/NEJM199111073251902
32. Ron E, Modan B, Boice JD Jr et al (1988) Tumors of the brain and nervous system after radiotherapy in childhood. N Engl J Med 319:1033-1039. https://doi.org/10.1056/NEJM198810203191601

33. Tucker MA, D’Angio GJ, Boice JD Jr et al (1987) Bone sarcomas linked to radiotherapy and $\mathrm{CT}$ in children. $\mathrm{N}$ Engl $\mathrm{J}$ Med 317:588-593. https://doi.org/10.1056/NEJM198709033171002

34. Eng C, Li FP, Abramson DH et al (1993) Mortality from second tumors among long-term survivors of retinoblastoma. J Natl Cancer Inst 85:1121-1128. https://doi.org/10.1093/jnci/85.14.1121

35. Hawkins MM, Wilson LM, Burton HS et al (1996) Radiotherapy, alkylating agents, and risk of bone cancer after childhood cancer. J Natl Cancer Inst 88:270-278. https://doi.org/10.1093/jnci/88.5. 270

36. Thompson DE, Mabuchi K, Ron E et al (1994) Cancer incidence in atomic bomb survivors. Part II: Solid tumors 1958-1987. Radiat Res 137:17-67 (Erratum in: Radiat Res 1994 Jul; 139: 129)

37. Hancock SL, Tucker MA, Hoppe RT (1993) Breast cancer after treatment of Hodgkin's disease. J Natl Cancer Inst 85:25-31. https://doi.org/10.1093/jnci/85.1.25

38. Bhatia S, Robison LL, Oberlin O et al (1996) Breast cancer and other second neoplasms after childhood Hodgkin's disease. N Engl J Med 334:745-751. https://doi.org/10.1056/NEJM19 9603213341201

39. van Kempen-Harteveld M, van Weel-Sipman M, Emmens $C$ et al (2003) Eye shielding during total body irradiation for bone marrow transplantation in children transplanted for a hematological disorder: risks and benefits. Bone Marrow Transplant 31:1151-1156. https://doi.org/10.1038/sj.bmt.1704076

40. Gruen A, Ebell W, Wlodarczyk W et al (2013) Total body irradiation (TBI) using helical tomotherapy in children and young adults undergoing stem cell transplantation. Radiat Oncol 8:92

41. Losert C, Shpani R, Kießling R et al (2019) Novel rotatable tabletop for total-body irradiation using a linac-based VMAT technique. Radiat Oncol 14:244. https://doi.org/10.1186/s13014-019-1445-3

42. Wong JYC, Filippi AR, Scorsetti M et al (2020) Total marrow and total lymphoid irradiation in bone marrow transplantation for acute leukaemia. Lancet Oncol 21:e477-e487. https://doi.org/10.1016/ S1470-2045(20)30342-9

43. Chabi S, To THV, Leavitt R et al (2021) Ultra-high-dose-rate FLASH and conventional-dose-rate irradiation differentially affect human acute lymphoblastic leukemia and normal hematopoiesis. Int J Radiat Oncol Biol Phys 109:819-829. https://doi.org/10.1016/ j.ijrobp.2020.10.012 